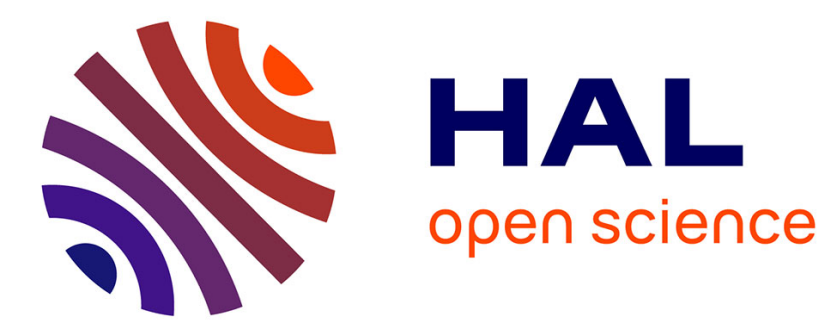

\title{
Productivity Growth and Pecuniary Knowledge Externalities: An Empirical Analysis of Agglomeration Economies in European Regions
}

\author{
Cristiano Antonelli, Pier Paolo Patrucco, Francesco Quatraro
}

\section{To cite this version:}

Cristiano Antonelli, Pier Paolo Patrucco, Francesco Quatraro. Productivity Growth and Pecuniary Knowledge Externalities: An Empirical Analysis of Agglomeration Economies in European Regions. Economic Geography, 2011, 87, pp.23-50. halshs-00727606

\section{HAL Id: halshs-00727606 \\ https://shs.hal.science/halshs-00727606}

Submitted on 4 Sep 2012

HAL is a multi-disciplinary open access archive for the deposit and dissemination of scientific research documents, whether they are published or not. The documents may come from teaching and research institutions in France or abroad, or from public or private research centers.
L'archive ouverte pluridisciplinaire HAL, est destinée au dépôt et à la diffusion de documents scientifiques de niveau recherche, publiés ou non, émanant des établissements d'enseignement et de recherche français ou étrangers, des laboratoires publics ou privés.

\section{(c)(1)}

Distributed under a Creative Commons Attribution| 4.0 International License 


\title{
Productivity growth and pecuniary knowledge externalities: An empirical analysis of agglomeration economies in European regions ${ }^{\star}$
}

\author{
Cristiano Antonelli ${ }^{\mathrm{a}, \mathrm{b}}$, Pier Paolo Patrucco ${ }^{\mathrm{a}, \mathrm{b}}$ and Francesco Quatraro ${ }^{\mathrm{a}, \mathrm{b}, \mathrm{c}}$ \\ a) Laboratorio di Economia dell'Innovazione "F. Momigliano" \\ Dipartimento di Economia "S. Cognetti de Martiis" \\ Università di Torino \\ Via Po 53 - 10124 Torino \\ b) BRICK (Bureau of Research on Innovation, Complexity and Knowledge) \\ Collegio Carlo Alberto, Moncalieri (Torino) \\ c) CNRS - GREDEG, University of Nice Sophia Antipolis
}

\begin{abstract}
The paper investigates the effects of agglomeration of technological activities on regional productivity growth, applying the notion of pecuniary knowledge externalities. These enable to appreciate both the gains and the losses associated with the regional concentration of knowledge generating activities. Both are two sides of the same coin. The former are due to the reduction in the prices of knowledge as input on its dedicated markets while the latter stem from the reduction in the prices for knowledge as an output. This allows us to contextualize the effect of geographical proximity on knowledge externalities, and their impact on regional growth. Our analysis leads to specify the hypothesis of an inverted U-shaped relationship between the agglomeration of innovation activities and productivity growth. The empirical analysis based upon a large sample of European regions in the years 1996-2003 supports the hypothesis that agglomeration yields diminishing net positive effects beyond a maximum.
\end{abstract}

Keywords: Geographical agglomeration; Knowledge transactions; Pecuniary knowledge externalities; Patents; Total factor productivity.

JEL Classification codes: O30; O31; O33; R11

Forthcoming in Economic Geography

\footnotetext{
${ }^{1}$ We wish to thank the participants to the Eurodite meeting held in Birmingham on 2008 April $8^{\text {th }}$ and $9^{\text {th }}$, to the Lunch Seminar of the Department of Economics at the University of Torino held on 2008 April $17^{\text {th }}$ to the conference "Knowledge for growth: European strategies for the knowledge economy" held in Toulouse on 2008 July 7-9, and to the Technology Transfer Society's Annual Meeting held on 2009 October $2^{\text {nd }}$ at the University of North Carolina at Greensboro, where preliminary versions of this paper have been presented. We acknowledge the stimulating comments of the Editors and three reviewers of this Journal, as well as the funding of the Collegio Carlo Alberto, the University of Torino with the local research grants in the years 2007 and 2008 and the European Union Directorate for Research, within the context of the Integrated Project EURODITE (Regional Trajectories to the Knowledge Economy: A Dynamic Model) Contract $\mathrm{nr}^{\circ} 006187$ (CIT3), in progress at the Fondazione Rosselli. We very much appreciated the very useful and stimulating comments of three referees and the Editor of this Journal, Yuko Aoyama.

^ Authorship is alphabetical and for the purposes of assessment of responsibility, each author contributes equally to the paper.
} 


\section{Introduction}

The relationship between agglomeration, externalities and regional growth has received renewed attention by economic geographers in the last decades. More specifically, elaborating upon the classical contribution of Alfred Marshall, scholars interested in the geography of innovation emphasized the idea that firms clustering in geographic space benefit from external economies and grow faster than isolated firms. This literature developed on the claim that geographical proximity, through unintentional contacts and interactions positively affected knowledge sharing and technological learning. Therefore, the so-called "pure" knowledge externalities, or knowledge spillovers have been highlighted as major drivers of technological progress and economic growth (Audretsch and Feldman, 1996; Jaffe, Trajtenberg and Henderson, 1993; Dumais, Ellison and Glaeser, 2002; Thompson, 2006).

Surprisingly enough, the possible negative effects of agglomeration on the exploitation of external knowledge received instead very little attention, as the implicit assumption underlying the predominant literature is that technological knowledge spills freely in the atmosphere and firms can simply benefit by "being there". Yet Jaffe (1986) had fully articulated and tested the hypothesis of the negative consequences of geographical proximity in terms of reduced appropriability of knowledge as an output: his results however did not receive due consideration.

In this paper we develop a framework to analyzing both the positive and the negative effects that agglomeration and knowledge externalities may yield on productivity dynamics. To this purpose we combine three different strands of literature, i.e. the economics of collective knowledge (Antonelli, 1999; Foray, 2004; von Hippel, 1988), 
the analysis of the markets for knowledge (Arora, Fosfuri and Gambardella, 2001) and the notion of pecuniary externalities, as formerly articulated by Tibor Scitovski (1954).

Our main argument is that intentional interactions among innovating agents are key to the success of knowledge production processes. The production of new knowledge requires instead the access to external knowledge as a source of new ideas able either to improve existing technologies or to provide the basis for brand new ones. Explicit market transactions can be effective solutions for knowledge exchange when supported by contractual modes such as long-term outsourcing contracts, equity agreements, bundling of license and good, patents' trade (Arora, Fosfuri, Gambardella, 2001). Geographical proximity helps the creation of markets for knowledge and complements the role of contractual arrangements due to the conditions of trust and reciprocity that characterize interactions within local contexts (Feldman, 1999).

The grafting of the notion of pecuniary externalities within this context proves to be far reaching. Insofar as markets for knowledge are supported by spatial proximity among innovating agents, pecuniary externalities hold when the price (cost) of goods (inputs) falls below the equilibrium level, so that economic agents obtain a real benefit when purchasing it. Knowledge is however both an input and an output in the knowledge production process. In view of this, the lowering of knowledge price is likely to yield both positive and negative effects, in terms of cost and revenue reduction respectively.

Specifically, we argue that the combined effects of positive and negative consequences of agglomeration are aligned along a quadratic relationship. In order to test this hypothesis we investigate the relationship between the agglomeration of technological 
activities and the growth of total factor productivity (TFP) for a large sample of European regions, observed in the time span ranging from 1995 to 2003 . We find evidence of an inverted U-shaped relation between technological agglomeration and productivity growth. The rest of the paper is organized as follows. Section 2.1 spells out the hypothesis that agglomeration bears both positive and negative effects in terms of knowledge externalities and that these can be captured by the notion of pecuniary knowledge externalities (henceforth PKE), while section 2.2 frames our hypotheses within a simple model. Section 3 articulates the methodology adopted to measure TFP following the growth accounting approach, presents the data set used for the empirical analysis and exhibits the econometric results of our study. Section 4 concludes and highlights the policy implications of our argument.

\section{Geographical proximity and knowledge spillovers: The discovery of PKE}

\subsection{The theory}

The concept of externalities has long attracted the interest of innovation scholars. According to the received Marshallian tradition (Meade, 1952; Viner, 1932), knowledge externalities are qualified as 'untraded' interdependencies among firms. These interdependencies are not mediated by the price mechanism and do not bear any actual costs for the firms to exploit their gains. Knowledge generated by a given firm is an unpaid factor that enters the production and innovation processes of other firms by means of accidental effects of co-location and spontaneous learning. After the early contributions on the local and systemic character of innovation processes, a wide body of theoretical and empirical literature has emerged aimed at applying the composite 
externalities framework to understanding the role of geographical space in the generation of technological knowledge and in the introduction of innovations.

In this direction, different kinds of externalities are said to contribute local accumulation of technological knowledge. An extensive body of empirical literature followed the original contribution of Glaeser, Kallal, Scheinkman and Shleifer (1992), which identified three types of knowledge externalities from which the advantages of agglomeration stem: the Marshall-Arrow-Romer (MAR) externalities that derive from the concentration of firms within a single industry; the Jacobs externalities, which instead are associated with the diversity of firms and industries within a given region; and the Porter externalities, according to which local competition among firms concentrated in the same industry favors local development.

In this vein, different authors (e.g. Deckle, 2002; Dumais, Ellison and Glaeser, 2002; Rosenthal and Strange, 2003) tested whether cross-fertilization of ideas, and consequently knowledge spillovers contribute regional productivity growth because of the technological homogeneity of firms clustered within the same industry, or rather because knowledge externalities are mobile across sectors and therefore benefit from the knowledge heterogeneity of the firms. The contributions in this body of scholarly research shares the idea that, thanks to social and institutional ties, localized accumulation of labor, capital and $R \& D$ are the unique requirements for knowledge spillovers and spontaneous learning from external sources to take place, and exert an unconditional positive effect on output and productivity growth. These are the basic tenets of the approach to pure knowledge spillovers. 
However, this authoritative analytical framework has been recently challenged both with regard to the understanding of the conditions under which agglomeration favors knowledge externalities and with regard to the types of externalities that spur local dynamics of innovation and growth (e.g., Thompson and Fox-Kean, 2005, also for a review of contributions).

In this paper we argue that economic geographers and innovation scholars would do well to rediscover the distinction introduced by Tibor Scitovski (1954) between technological externalities and pecuniary externalities. The former are benefits accruing from others' activities that are not mediated by market mechanisms, while the latter describe benefits accruing from others' activities that are mediated by markets through the price system ${ }^{2}$.

Knowledge spillovers have been seen as a case of pure technological externalities, being knowledge available at no costs in local contexts, and freely accessible by everyone "being there". Yet, most of the literature analyzing the dynamics of knowledge spillovers falls in the trap of explaining the supposed evidence of dynamic increasing returns at the local level by invoking processes that typically apply to pecuniary externalities, like economies of specialization and labor market economies (Breschi and Lissoni, 2001b).

Differently from the established literature, we argue that knowledge externalities are mostly pecuniary in their own right, rather than 'pure externalities'. The combination of the collective knowledge approach with the literature on markets for technologies

\footnotetext{
${ }^{2}$ In this respect, both MAR and Jacobs' externalities may turn out to be either pecuniary or technological.
} 
allows for proposing the new concept of PKE: the benefits from local knowledge pools are not due to a generic intangible atmosphere, but they are the outcome of intentional actions and organized transactions carried out in the marketplace.

The generation of technological knowledge can be depicted as an outcome of a collective undertaking strongly influenced by the availability of local sources of knowledge and by the way in which interactions are organized and carried out (Allen, 1983; von Hippel 1988). Specifically, technological knowledge, as it is used and generated by firms, stems from the combination of two basic inputs, i.e. internal and external knowledge. The intentional participation of firms in organized knowledge exchanges makes possible the acquisition of knowledge sourced externally in other firms (e.g., clients, suppliers, rivals) and institutions (e.g., universities, R\&D labs, TTOs) (Dicken and Malmberg, 2001; Nicholas, 2009). Internal and external knowledge represent two strongly complementary inputs and none of the two inputs may fall without a certain threshold without harming the entire knowledge production process (Antonelli, 1999).

The innovative performance of the firms does not depend only on their internal R\&D resources but also and increasingly, on their ability to acquire complementary competencies from external sources through a wide array of mechanisms. These are the result of the increasing trend toward outsourcing highly specialised phases of production, as well as the provision and purchase of specific and complementary intermediate inputs involving both upstream (users) and downstream actors (contractors and subcontractors) (Herrigel and Zeitlin, 2000), and include, for instance: a) pure research contracts with research laboratories and universities; b) technology transfer 
agreements with TTOs and public infrastructures; c) technological consultancy provided by knowledge intensive service firms; d) production-oriented agreements or joint manufacturing agreements.

In such a context of increasing compositeness of the innovation process and its organization, firms need to undertake specific activities and efforts to integrate such external knowledge, which can be very idiosyncratic and different from those already possessed, into their internal knowledge production processes (Pisano, 1996; Patrucco, 2009). In other words, access to external knowledge is harmed by the efforts agents must face to screen the markets of technological knowledge, and then acquire the relevant portion of knowledge produced and sourced externally (Agrawal, Cockburn and McHale, 2006; Beugelsdijk, 2007).

The analysis of the mechanisms through which knowledge results as a collective undertaking bears a new emphasis on the role of interactions for the working of the markets for knowledge. The crucial analytical achievement of the research on the markets for knowledge (e.g., Arora, Fosfuri and Gambardella, 2001) is the appreciation that contractual devices and geographical proximity reduce the price of trading and exchanging of bodies of knowledge in the market place between the players of reiterated interactions. Hence, regional proximity complements and actually makes possible the markets for knowledge and the flows of transactions between, for instance, manufacturing firms, academic laboratories, new technology-based firms, consultants and knowledge-intensive services. 
Lynn Zucker and her colleagues (Zucker, Darby, and Armstrong, 1998; Zucker, Darby, Brewer, 1998; see also Nakamura and Odagiri, 2005) provided a systematic and original support to the increasing importance of organized-transactions in the markets for knowledge for the dissemination and acquisition of technological knowledge. Proximity eases the interactions between venture capitalists, skilled management, and the scientific community so as to increase the probability that new fertile knowledge is exploited timely and effectively. Organized-transactions are supported not only by an array of complementary institutional conditions such as intellectual property rights, long terms contracts and spatial proximity. The latter provides favorable conditions to the creation of markets for knowledge, so that agglomeration and interactions complement rather then substitute transactions. Proximity through high-quality conditions of trust and reciprocity also enables repeated interactions between co-localized firms (Feser, 2002; Gossling, 2003) that lead to more effective market mechanisms, which increase the opportunities of the actual exploitation of technological knowledge.

The chance to benefit from the lower prices at which actors can access and buy external knowledge drives economic organizations to outsourcing specific pieces of knowledge, creating a sort of intermediary market for knowledge producers (Arora, Fosfuri and Gambardella, 2001). Organizations enter the markets for knowledge, and increase the density and frequency of knowledge transactions, because the price they pay to buy technological knowledge sourced externally through knowledge transactions is lower than the cost they would face in the case they choose to produce the same portion of knowledge through vertical integration of R\&D. 
However, the more complex and articulated this process, the larger the number of the actors involved and embedded in the local net of knowledge exchanges, the more difficult are contract to be enforced, and the lower the opportunity to appropriate and secure the rights for the exclusive exploitation and valorization of proprietary knowledge (Aharonson, Baum and Feldman, 2007). Markets for knowledge turn out to be efficient mechanisms for knowledge transactions only from a static viewpoint. Dynamic efficiency is secured only unless a critical number of transactions are reached. Beyond a threshold level of transactions diminishing returns are likely to arise. Proximity favors repeated interactions that in turn easily lead to relaxing the control conditions for the exclusive use of knowledge and reduce the opportunities for its direct exploitation as a good or indirect valorization as an input into downstream innovation processes. The mobility of qualified personnel (e.g., Gossling, 2003) is for instance a major factor in the reduction of the actual appropriation of proprietary knowledge. Firms localized in a region with high levels of concentration of research activities share their basic knowledge because they access the same pools of local knowledge with the clear effect to attracting and increasing the entry of new competitors in the local markets for knowledge.

The reduction in the price for knowledge as an output affects also the efforts to secure the indirect valorization of the proprietary knowledge internally by means of its vertical integration and use in downstream activities where it becomes an input into the introduction of product and process innovation and the production of other goods so that it can be sold embodied. Proximity in fact favors not only the leakage of disembodied knowledge upstream, but also, downstream, the imitation of innovated goods by agents localized nearby (Levin et al., 1987). 
We are now able to articulate the notion of PKE. Pecuniary knowledge externalities consist of the indirect interdependences among actors that take place in the markets for knowledge inputs via the price system. They apply when firms acquire inputs (and sell output) at costs (prices) that are lower (higher) than equilibrium levels because of specific structural factors. Most if not all external knowledge, in fact, is acquired by means of user-producer interactions that are realized through market transactions among sellers and customers of intermediary and capital goods. Hence pecuniary externalities apply, instead of technological externalities, because the external effects that shape the generation and exploitation of knowledge is channeled by transactions and hence take place via the price mechanism (Antonelli, 2008a and b).

This approach seems at the same time closer to the actual evidence of knowledge generation processes and more inclusive as it enables to accounting for both the gains and the losses engendered by knowledge externalities on the markets for knowledge. While the former consist of the advantages associated with lower prices of external knowledge as an input due to more effective knowledge transactions, the latter are represented by the reduction in the actual price for knowledge as an output that firms can command when they try and sell their knowledge or try and make a direct use to improve their productivity. Both the positive and negative effects of PKE depend upon the density of innovative agents co-localized in the same region. It is clear that the larger is the density of innovative agents and the larger is the opportunity to acquire external knowledge, as an indispensable input, by means of market exchanges, but is also clear that the larger is the density of innovative agents and the larger are the losses in terms of reduced price for proprietary knowledge as an output. 
The combination of positive and negative effects explains the quadratic relationship between agglomeration and productivity growth. The dynamics of PKE are such that an increase in the agglomeration of knowledge generating activities is expected to yield net positive effects, so long as the negative effects in terms of appropriability losses and excess supply overtake the positive effects due to lower purchasing prices. This quadratic relationship is likely to hold irrespective of the degree of coherence of the structure of the local knowledge base. Because of the need of acquiring external resources, knowledge is likely to be heterogeneous, and variety may yield positive effects in terms of Jacobs' knowledge externalities. Yet, the distinction between related and unrelated variety (Frenken et al., 2007) help us in qualifying the degree of heterogeneity of knowledge and the extent to which external knowledge can be efficiently absorbed and used. When the technological distance between different knowledge bases is too high, and these are divergent and unrelated, acquiring external knowledge is difficult and variety is likely to harm the dynamics of PKE. Viceversa, heterogeneity of knowledge and Jacobs knowledge externalities are likely to display their advantages on the dynamics of PKE when internal and external knowledge bases are characterized by high degree of relatedness and coherence ${ }^{3}$. Different variety regimes may thus affect the extent to which PKE display their effect, but are not likely to fully neutralize them ${ }^{4}$. When knowledge pools are characterized by a relatively high degree of related variety, one would expect that increasing density of technological activities would lead to a somewhat flatter quadratic curve, the maximum of which

\footnotetext{
${ }^{3}$ In this respect, we characterize knowledge as a heterogeneous good within given boundaries of proximity and relatedness of the different knowledge bases.

${ }^{4}$ For example, in a context characterized by a large number of highly specialized knowledge components, the negative effects on appropriability conditions may not hold across different technological areas, but would apply within each technological area as the within density increases. In this direction, it would be interesting to combine the analysis of pecuniary knowledge externalities with the concepts of diversity, balance and disparity (Stirling, 2007; van der Berg, 2008), but it is well beyond the scope of this paper.
} 
would be lower than in a context characterized by a relatively high degree of unrelated variety.

Within this framework, the role of 'pure externalities' can be reconsidered. Untraded interdependencies are not the solely factors, and not even the predominant ones, shaping the dynamic increasing returns observed in technological clusters. Pure technological externalities, however, do add on to the effects of PKE on productivity gains. They are actually supposed to positively affect innovation dynamics by means of a generalized increase of locally available technological opportunities. This would amount to a change in the intercept in the quadratic curve, according to which PKE in a context characterized also by strong 'pure externalities' would be represented by an inverted-U curve wherein productivity gains for each level of agglomeration are higher than in a context characterized by weaker 'pure externalities'

\subsection{The Model}

Our hypothesis is that agglomeration of knowledge intensive activities yields diminishing returns beyond a maximum. Agglomeration in fact engenders both positive and negative effects in terms of PKE. Net pecuniary gains from knowledge externalities refer to the productivity gains stemming from the access to cheaper external knowledge available in the local markets for knowledge mediated by the price system, after accounting for the losses engendered by the negative effects of agglomeration on the appropriation of knowledge as an output and hence on its market price.

PKE enable to account both for the gross gains that are possible when the actual price of external knowledge falls below the equilibrium levels due to the relative abundance of 
external knowledge sources and the gross losses that stem from reduced appropriability and exclusive exploitation when knowledge as an output is valorized and feed the downstream introduction of product and process innovations. Net PKE are the algebraic sum of the two and exert a direct effect on the growth of total factor productivity of colocalized firms following a quadratic function of the density of knowledge intensive activities.

The argument elaborated may be clarified by articulating a simple model. Let's suppose that a local (say regional) economy is represented by a general production function:

$$
Y=A f(K, L)
$$

Where $Y$ represents a measure of output, $A$ is a measure of production efficiency, while $K$ and $L$ are capital and labour inputs. The efficiency of production, $A$, is usually referred to as total factor productivity (TFP). The TFP indicator is likely to capture a wide body of phenomena that make output increase more than proportionally with respect to the increase in production inputs ${ }^{5}$. For the sake of simplicity, let us argue that $A$ is a (linear) function of the whole body of technological knowledge available in the region ${ }^{6}$ :

$$
A=f(T K)
$$

According to Griliches (1979), the generation of knowledge may be viewed as the outcome of a knowledge production process, represented by a knowledge production

\footnotetext{
${ }^{5}$ We acknowledge that differences in levels and rates of change of TFP may be subject to non-univocal interpretations. While Solow (1957) associated TFP growth with technological advances, Abramovitz (1956) defined the residual as some sort of measure of ignorance. Nonetheless it remains a useful signalling device, in that it provides useful hints on where the attention of the analysts should focus (Maddison, 1987).

${ }^{6}$ The triggering effects of innovation on productivity growth represent a well established fact in the economic literature dealing with innovation and technological change. The relevance for regional economic growth has been acknowledge since the seminal work by Francois Perroux (1955).
} 
function (KPF). Our KPF relates the knowledge output to the employment of two knowledge inputs, i.e. internal and external knowledge (respectively $I K$ and $E K$ ):

$T K=g(I K, E K)$

According to a wide body of literature in the economics of knowledge, internal and external knowledge are both key and complementary inputs for the generation of new technological knowledge. In view of this the process of knowledge production might hardly take place should any of these two inputs be missing.

The complementarity between internal resources and external ones is emphasized bearing in mind the extensive qualitative and quantitative evidence on the organization of innovation processes. Building upon the research inaugurated by Cohen and Levinthal (1989 and 1990), scholars confirm that firms purposefully establish selective interactions within networks precisely to access complementary knowledge inputs? Such literature shows that the production of innovation and new technological knowledge by means of vertically-integrated $R \& D$ activities has been progressively substituted by a net of knowledge transactions because a single firm is not able to invest the sufficient amount of resources to develop new knowledge through a fully internal process. The use of external knowledge inputs may yield clear advantages in overcoming the technological and financial limitations of in-house innovation, and may enlarge technological opportunities through the search of the external environment. At the same time, some internal technological competencies are necessary to explore for the more appropriate external knowledge available, as well as to enable an efficient absorption and use of the knowledge sourced externally. In other words, a firm does

\footnotetext{
${ }^{7}$ For recent theoretical and empirical contributions on the complementarity between internal and external knowledge inputs, see for instance Zahra and George, 2002; Roper, Du and Love, 2008; Love and Roper, 2009, which elaborate, further develop and test the original intuition by Cohen and Levinthal, 1989). For some qualitative and quantitative evidence at the geographical level see for instance Patrucco, 2005 and Giuliani, 2007.
} 
need to access other knowledge sources in order to create new knowledge since the collapse on internally developed knowledge would necessarily lead to exhaustion of technological opportunities, which would not be fed by new stimuli. On the other hand, by relying only on external knowledge, one would not develop the conditions to absorb it ${ }^{8}$.

External knowledge is an essential and non-disposable input as much as internal learning and R\&D activities: none of them can be suppressed or reduced to nihil (Nelson, 1982). For these reasons, the access to external knowledge is a necessary, though not sufficient, condition for the production of new knowledge, which cannot be surrogated in any way (Foray, 2004; Antonelli, 1999). It turns out that such inputs cannot be considered as substitute, not even imperfect, in the KPF, but they must be considered as strictly complementary with very low levels of the elasticity of substitution among the two production factors.

Hence the specification of the knowledge production function is far from the traditional Cobb-Douglas and takes all the characteristic form of a generic multiplicative relationship (Kremer, 1993; Patrucco, 2008).

This leads us to specify the total costs of knowledge production as follows:

$$
T C K=h(v, I K, z, E K)
$$

\footnotetext{
${ }^{8}$ These arguments may translate into the specification of a knowledge production function with two inputs, namely internal and external knowledge, where the marginal rate of substitution is far lower than the standard unit level that characterizes the Cobb Douglas production function.
} 
Where $v$ and $z$ are respectively the unit price of internal and external knowledge. While $v$ may be viewed as the cost economic agents must bear to commit resources to learning and $R \& D$ activities, $z$ represents the price at which knowledge is sold on local markets

The core of pecuniary knowledge lies in the relationship between the price of external knowledge as an indispensable input into the production and the price of knowledge as an output. Let us consider first the effects of the purchasing price of external knowledge as an non-disposable input. It is easy to proof that in a traditional setting characterized by a Cobb-Douglas, the $T C K$ would have increased as $z$ increases, but at a decreasing rate as an effect of imperfect substitutability between $I K$ and $E K$. However, we have posited that in the KPF, $I K$ and $E K$ are not substitutes but complementary inputs which are in a multiplicative relationships with each other. Therefore we may characterize equation (4) as follows:

$$
\frac{\partial T C K}{\partial z}>\quad ; \quad \frac{\partial T C K}{\partial}>0
$$

so that the $T C K$ look like a power function of $z$, as in Figure 1.

\section{INSERT FIGURE 1 ABOUT HERE}

The first side of the PKE hypothesis consists in the fall of the price for knowledge as an input on local markets below the equilibrium price as an effect of increased availability on local knowledge markets. Let us now consider the second nested effect on the revenue of the firms that generate knowledge as an output and try and valorize it.

In order to have a complete assessment of both effects, in fact we need to explore the relationship between the price at which knowledge is sold and the revenues stemming from its sale. Since knowledge produced by agent $i$ represents external knowledge for 
all other agents, it may be sold on local markets at price $z$. According to this, we may also specify the total gross revenue stemming from knowledge selling:

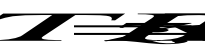

The gains and the losses associated to the working of PKE can now be fully appreciated with a few passages. The argument elaborated in Section 2 leads us to spell out the following relationship between the price of external of external knowledge and the density of knowledge generating agents:

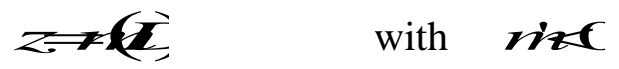

The intuition is straightforward, and is much in line with Scitovski's analysis of pecuniary externalities. The agglomeration of knowledge production activities leads to an expansion of the knowledge output so that the price for knowledge on local markets falls down. Since knowledge is both an input and an output of this production process, the mechanisms of PKE yield both positive and negative effects, according to the side of the production process one focuses on (input purchasing vs. output selling). On the one hand, the lowering of the price for the external knowledge input lowers the total costs for knowledge production. On the other hand, the knowledge producing agent turns out to sell its knowledge output at a lower price. This relationship is much clear when plotting a diagram of $T C K$ and $T R K$ as a function of $D$ (see Figure 2).

\section{INSERT FIGURE 2 ABOUT HERE}

Following Scitovski, pecuniary externalities apply when prices are below the equilibrium level. The full effects of PKE may be now grasped when comparing the gains and the losses stemming from knowledge production in presence of externalities with those obtained in a no-externalities context. Indeed, in the latter the price of external knowledge is not supposed to vary according to $D$. Therefore we may represent both the costs $\left(\mathrm{TCK}^{*}\right)$ and the revenues $\left(\mathrm{TRK}^{*}\right)$ at equilibrium prices as a straight line 
parallel to the $\mathrm{x}$-axis in Figure 3 . In the top diagram, the equilibrium cost line is compared with the TCK curve as a function of $D$. The difference between the two curves represents the benefits, or pecuniary gains $(P G)$, that stems from the lowering of knowledge production costs. In the same vein, in the mid diagram we compare the equilibrium revenue line with the $R T K$ line as a function of $D$. The difference between these two lines stands for the pecuniary losses $(P L)$ that stems from the lowering of the revenues from knowledge production.

\section{INSERT FIGURE 3 ABOUT HERE}

Therefore, the effects of PKE are germane to both the costs and the revenue sides. The assessment of them both in turn enables to determine the actual profits for knowledge producing agents. "When these benefits accrue the firms, in the form of their profits, they are pecuniary external economies" (Scitovski, 1954: p. 147). The bottom diagram allows us to compare $P G$ and $P L$, so as to introduce the concept of net pecuniary gains $(N P G)$ as the difference between the former and the latter.

From the diagram it is clear that the $N P G$ increase as $D$ increases up to a point after which the NPG start decreasing. In other words, the NPG function may well be approximated by a quadratic function with a downward concavity. Formally the relationship is:

$$
N P G=w(D) \quad \text { with: } \begin{array}{ll} 
& w^{\prime}>0 \quad \\
w^{\prime}=0 \text { if } & D=D^{*} \\
w^{\prime}<0 & D>D^{*}
\end{array}
$$

The analysis articulated so far has shows that PKE are likely to yield both positive and negative effects, so that their net benefits exhibit a quadratic relationship with the density of knowledge generating agents within local contexts. We may now derive the effects on total factor productivity through a few more passages. 
Insofar as there are positive net pecuniary gains for knowledge generating firms, new agents would be willing to enter the local markets for knowledge due to the prospective profit opportunities. The growth of knowledge generating agents $(N)$ therefore turns out to be a positive function of $N P G$. These are in turn a quadratic function of $D$. If we assume $N$ to proportionally grow as $N P G$ increases, we may approximate the growth of $N$ as a quadratic function of $D$ as well:

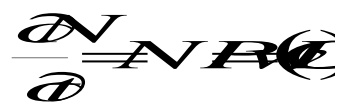

The growth of the total knowledge $(T K)$ in turn grows as an effect of the increasing number of knowledge generating agents in the area:

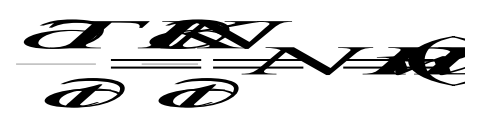

Finally, let us recall the relationship expressed by equation (2). According to that, we may argue that TFP grows as a function of TK growth:

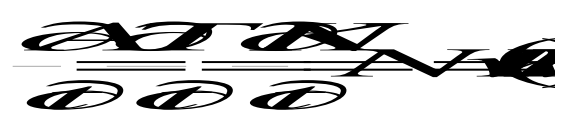

According to this chain of nested relationships, the growth rate of $A$ turns out to be a quadratic function of the density $(D)$ of knowledge creating agents within the local context. Figure 4 helps clarifying the passages that lead to this conclusion. Differences in the degree of internal coherence of the local knowledge base are likely to shape the curvature of the parabola in bottom diagram, while the relative strength of complementary 'pure externalities' is likely to shift it upwards.

\section{INSERT FIGURE 4 ABOUT HERE}

In conclusion, PKE are likely to affect productivity dynamics in local contexts, so that the TFP growth rate turns out to be a quadratic function of the density of innovating agents. In what follows we provide an empirical test for the validity of such hypotheses. 


\section{The evidence of PKE}

\subsection{Methodology}

This section provides the basic methodology to investigate the relationship between TFP and the agglomeration of technological activities, as driven by PKE.

In order to test our working hypotheses, we first need to measure total factor productivity (TFP), $A_{i t}$, following the growth accounting approach (Solow, 1957; Jorgenson, 1995; OECD, 2001). Let us start by assuming that the regional economy can be represented by a Cobb-Douglas production function with constant returns to scale:

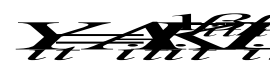

where $L_{i t}$ is represents labour services rendered in the region $i$ at the time $t, K_{i t}$ stands for capital services in the region $i$ at the time $t$, and $A_{i t}$ is the level of TFP in the region $i$ at the time $t$.

The yearly output elastiticity of labour, $\beta_{i t}$, is calculated for each region as the total income share of employment compensation ${ }^{9}$. Then the annual growth rate of regional TFP is calculated as usual in the following way:

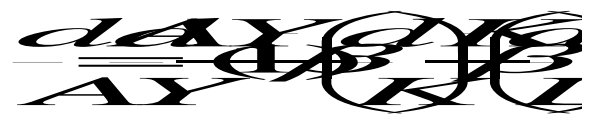

Our basic hypothesis is that the net benefits from PKE grow until a critical mass of agents within the system is reached. The further increase in the density of agents makes the pecuniary gains grow less than proportionately with respect to pecuniary losses.

\footnotetext{
${ }^{9}$ In the discrete approximation of the Divisia index, the growth rate of the production factor is weighted by the two years average of the output elasticity. Therefore, in Equation (11) $\bar{\beta}$ is the two years average output elasticity of labour.
} 
The test of such hypothesis needs for modeling the growth rate of TFP as a function of the density of technological activities, which we call $D_{i t}$. Moreover, it is usual in this kind of empirical settings to include the lagged value of TFP, $1 \mathbf{m} \mathbf{4}_{t-1}$, in order to capture the possibility of mean reversion. In general terms, this relationship can be written as follows:

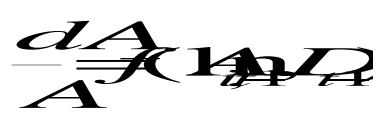

In particular, our line of reasoning leads us to characterize Equation (6) as follows:

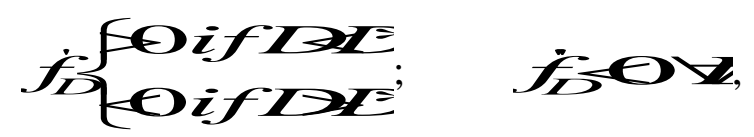

Where $D^{*}$ is the threshold level of the density of technological activities. A convenient way to represent such a kind of relationship can be found in the following structural equation:

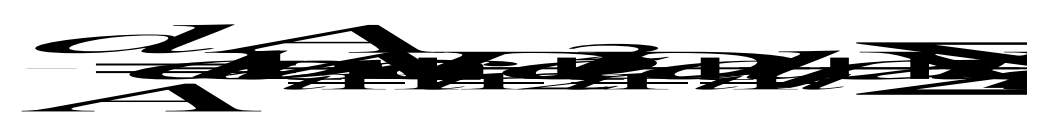

Where $X_{t-1}$ represents a vector of control variables and the error term is decomposed in $\rho_{i}$ and $\Sigma \psi t$, which are respectively region and time effects, and the error component $\varepsilon_{i t}$. Equation (13) proposes a quadratic relationship between TFP growth and density, where we expect $c_{1}>0$ and $c_{2}<0$.

Equation (13) can be estimated through traditional fixed effect estimators for panel data. However, when analyzing the determinants of TFP growth at the regional level a special focus must be devoted to locational aspects. Regional scientists have indeed showed that geographical proximity may affect correlation between economic variables. 
While the traditional econometric approach has mostly neglected this problem, a new body of literature has recently developed, dealing with the identification of estimators able to account for both spatial dependence between the relationships between observations and spatial heterogeneity in the empirical model to be estimated. Former treatment of spatial econometric issues can be found in Anselin (1988), subsequently extended by Le Sage (1999).

The idea behind the concept of spatial dependence is straightforward. The properties of economic and social activities of an observed individual are likely to influence economic and social activities of neighbour individuals. Formally this relationship can be expressed as follows:

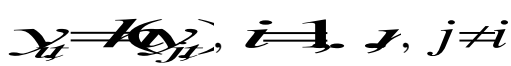

The dependence can therefore be among several observations. If this is the case, structural forms like equation (13) are likely to produce a bias the estimation results. There are different ways to cope with this issue. First, one may apply spatial filters to the sample data, so as to remove the spatial structure and then apply traditional estimation techniques. Second, the relationship can be reframed using a spatial error model (SEM), in which the error term is further decomposed so as to include a spatial autocorrelation coefficient. Third, one may apple the spatial autoregressive model (SAR), which consists of including the spatially lagged dependent variable in the structural equation.

We decided to compare the SAR and SEM models in order to have a direct assessment of the spatial dependence of productivity growth between close regions. However, most of the existing literature on spatial econometrics propose estimator appropriate for 
cross-sectional data. Given the panel data structure of our sample, we therefore follow Elhorst (2003) extending Equation (13) so as to obtain the SAR (Eq. 15) and the SEM (Eq. 16) specifications:

$$
\begin{aligned}
& \frac{d A}{A}=\xi W\left(\frac{d A}{A}\right)+b \ln A_{i, t-1}+c_{1} D_{t-1}+c_{2} D_{t-1}^{2}+ \\
& +d X_{t-1}+\rho_{i}+\sum \psi t+\varepsilon_{i, t} \\
& \frac{d A}{A}=b \ln A_{i, t-1}+c_{1} D_{t-1}+c_{2} D_{t-1}^{2}+d X_{t-1}+\rho_{i}+\sum \psi t+\varepsilon_{i, t}+\phi_{t} \\
& \phi_{t}=\delta W \phi_{t}+\mu_{t}, E\left(\mu_{t}\right)=0, E\left(\mu_{t} \mu_{t}^{\prime}\right)=\sigma^{2} I_{N}
\end{aligned}
$$

Where $\xi$ is referred to as spatially autoregressive coefficient and $W$ is a weighting matrix. This latter can be defined either as a contiguity or as a normalized distance matrix. In the analysis that follows we chose the second alternative, by building a symmetric matrix reporting the distance in kilometres among the city centre of the regional chief towns.

\subsection{The data}

In order to investigate the relationships between economic performances on the one hand, and the density of innovation activities on the other hand, the data were mainly drawn from the Eurostat regional statistics, obtaining an unbalanced panel of 186 European regions, observed in the time span ranging from 1995 to 2003.

As far as TFP is concerned, we need output, labour and capital services, and the labour and capital shares. As a measure of output we used the real GDP (2000 constant prices). Eurostat also provides with estimation of capital stock and employment, although it 
does not provide data about hours worked at the regional level. For this reason we used average hours worked at the country level provided by the Groningen Growth and Development Centre ${ }^{10}$, and then calculate total hours worked. Although this does not allow us to appreciate cross-regional difference in average hours worked, nonetheless it allows us to account at least for cross-country differences. The labour share is calculated using data on the compensation of employees and the GDP, while capital share is calculated as 1 minus labour share.

As far as the explanatory variables are concerned, we need a measure of innovation activity. To this purpose we used the number of patent applications submitted to the European Patent Office (EPO), provided by the Eurostat regional science and technology indicators. Patent applications are assigned to regions according to inventor's address. Moreover each patent is assigned to one or more technological classes, according to the international patent classification (IPC) ${ }^{11}$.

The actual measurement of externalities, as well as the distinction between pure and pecuniary externalities, represents a very difficult task for empirical economists (Breschi and Lissoni, 2001a and b) ${ }^{12}$. This is even more problematic in firm-level

\footnotetext{
${ }^{10}$ www.ggdc.net.

${ }^{11}$ Patent applications as economic indicators present well-known drawbacks. They can be summarized in their sector-specificity, the existence of non patentable innovations and the fact that they are not the only protecting tool. Moreover the propensity to patent tends to vary over time as a function of the cost of patenting, and it is more likely to feature large firms (Pavitt, 1985; Levin et al., 1987; Griliches, 1990). However, previous studies highlighted the usefulness of patents as measures of production of new knowledge, above all in the context of analyses of innovation performances at the aggregate regional level (Acs et al., 2002).

12 Among the difficulties in measuring knowledge externalities, it is useful to recall here that we focus on the analysis of externalities at the regional level and look for the effect of geographical on knowledge flows channeled by market transactions. However, it is fair to acknowledge that recent literature, including evidence on co-patenting activities, highlights also the fact that networks between nonneighboring actors provide effective channels for knowledge flows (see for instance, Breschi and Lissoni, 2001a, b, and, for a more general perspective on the role of geographical proximity for knowledge exchange, Boschma, 2005). Our analysis of within-regions externalities leaves out the knowledge flows occurring between non-neighboring regions, and this should be taken into account when considering our
} 
studies, where the object of analysis is the identification of the effects of external knowledge on firm's innovation output. In this paper we adopt an indirect approach to the measurement of PKE. The discussion conducted in Section 2 indeed lead us to postulate that PKE shape the relationship between the density of technological activity and productivity growth, giving rise to a quadratic curve.

Indeed externalities are likely to emerge in contexts shaped by geographical agglomeration of technological activities. This is even clearer when PKE are at stake, where the formation of local markets for knowledge is likely to affect the efficiency of the exploitation of knowledge sourced externally. We describe technological agglomeration through a measure of the density of technological activities, and more precisely as the relationship between the scale of such activities and the size of the population that generate, use and exploit technological knowledge ${ }^{13}$. The empirical test of our hypotheses should provide support to the existence of PKE. For what concerns the actual measurement of the density, $D$, we take the ratio between the regional levels of patent applications ${ }^{14}$ and the regional level of employment (Quatraro, 2009a). We therefore assume that knowledge externalities arise within regional areas, and that negative effects arise when the density of innovating agents within the production system is too high ${ }^{15}$ :

results. Knowledge flows between non-neighboring regions would be better analyzed by implementing a micro-level study focused on co-patentees.

${ }^{13}$ Other approaches would rather have preferred the total number of patents as a measure of technological agglomeration. However, in our view agglomeration better refers to the magnitude of a phenomenon, as compared to the context in which it takes place. Therefore, in practice we measure technological agglomeration as the ratio between the total number of patents and the total number of employees in the region. This view is also consistent with the conventional use.

${ }^{14}$ Due to the high variance of patenting activity over time, we decided to calculate the 5-years moving average at each year.

${ }^{15}$ NUTS 2 regions are used in this analysis. We are aware of the problems raising by using administrative boundaries to define areas characterized by agglomerations, yet the available data do not allow to purse such a large scale analysis by refining the concept of local contexts. 
$D_{i, t}=\frac{P A T_{i t}}{L_{i t}}$

The vector of control variables consists of the following indicators. First of al, we define an index of technological homogeneity (SPEC) of regions by using the Hirschman-Herfindal index. In particular, the IPC classification is organized at different levels of aggregation. We decided to take the one digit classification, so that eight classes can be distinguished, ranging from $\mathrm{A}$ to $\mathrm{H}$. Therefore for each region at each year we were able to calculate the share of patents within each class. The index thus turns out to be:

$\operatorname{SPEC}_{i, t}=\sum_{j=1}^{8} s_{i, j, t}^{2}$

Where $s_{i j t}$ is the share of technological class $j$ in the overall set of patent applications at time $t$ in region $i$. The higher (lower) is the index, the higher (lower) is the technological homogeneity of regions.

As for the control variables, one needs to control for the impact on the one hand of traditional agglomeration economies, on the other hand of changing regional industrial specialization, so as to reduce the possible biases in our estimates (Quatraro, 2009b). Following Crescenzi et al. (2007), the effects agglomeration economies are captured by the variable $A G G L$, which is calculated as the (log) ratio between regional population and size (square kilometres). The changing specialization is instead proxied by $L O Q$, i.e. the location quotient for manufacturing added value.

Table 1 shows the descriptive statistics for the key variables, reporting the within and between values for the regions considered in our analysis. This preliminary data reveal that the variables are characterized by a fairly significant degree of variance, both 
within and between regions. On average, the cross-regional dispersion is higher than that observed within regions over time. Moreover, the dispersion of the density index within regions is higher than that of the homogeneity index, while the reverse applies for what concerns the cross-regional variance.

\section{>> INSERT TABLE 1 ABOUT HERE $<<<$}

To gain a better understanding of cross-regional differences in our sample, in Figure 2 we report the maps that assign the regions to the observed levels of patent applications per thousand workers. Such diagrams provide some interesting preliminary information. Fist of all, in 1996 one may observe a great deal of concentration of patenting activity in Central European regions. The German areas of Stuttgart, Oberbayern and Rheinhessen appear to fall in the uppermost class. Comparable levels may be found also in the Dutch region of Noord-Brabant and the UK region of East Anglia. In the second class, which includes values between 0.017 and 0.028 , one can find the rest of central German regions and the Rhone-Alpes area in France. Moreover, most of Finnish regions fall in this class, along with Essex, Berkshire and Gloucestershire in the UK, and Mellansveringe and Sydsverige in Sweden. The third rank class contains the Upper Norrland and the Middle Sweden regions, as well as some regions in the North of Germany. Furthermore, one may also include the Italian regions of Piedmont, Lombardy, Emilia Romagna and Abruzzi, along with the Ile-de-France and most of English and Scottish regions. It follows that the rest of European ergions in Spain, Greece, Southern Italy and Eastern Europe are in the lowermost classes, showing a clear divide between Northern and Southern Europe.

\section{> FIGURE 5 ABOUT HERE <<}

The bottom diagram in Figure 5 shows the regional distribution of per worker patent applications in 2003. One may easily observe that the polarization between Northern 
and Southern Europe is quite persistent. However, there are some relevant changes to the relative distribution within the core of patenting regions. In particular, all areas in central Germany are now in the uppermost class, along with the south of Sweden. Some other regions also show a significant improvement, like the Emilia Romagna and Marche in Italy, and the Bretagne in France. On the other hand, the regions in the north of Sweden exhibit a clear reduction in the relative levels of patenting. The same applies to the Franche-Comté, the Bourgogne and the Champagne-Ardenne regions in France, as well as to Scottish and Welsh areas in the UK.

This descriptive evidence shows that there is a significant variance across European regions for all variables. High levels of agglomerations seem to feature mostly some areas of the UK and Germany, along with some Swedish regions. Moreover, the density of innovating agents appears to vary to a great extent also over time, within the observed regional contexts. For this reason in what follows we will use panel data techniques in the econometric test.

\subsection{Econometric results}

In the empirical analysis we estimate the shape and the extent of positive and negative feedbacks from the agglomeration of innovation activities to the dynamics of productivity.

Tables 2 and 3 report the results for the fixed effects estimation of equation (13), providing a number of robustness checks to our hypothesis about the existence of a quadratic relationship between productivity growth and the density of knowledge generation activities. In the first column one may find a baseline specification of a linear 
relationship between $d A / A$ and $D$. As expected, the coefficient on the lagged level of productivity is negative and significant, while the coefficient on $D$ is positive and weakly significant. We then introduce in the regression the quadratic term for $D$. The results seem to be now stronger. All coefficients are significant at $1 \%$, and the coefficients on $D$ and on $D^{2}$ show the expected sign, i.e. positive and negative respectively. This provides clear support to the idea that the agglomeration of innovation activities yields net positive gains that are increasing until the density of innovating agents reaches a maximum beyond which they start decreasing. In model (3) we add a control variable (SPEC) which is related to the degree of regional technological specialization. One may note that the only coefficients that preserve their signs, and keep being statistically significant, are $D$ and $D^{2}$. The same applies when we also add the interaction term between $D$ and SPEC (model 4). However, our results may still be biased due to omission of relevant variables, like traditional agglomeration economies or the location quotient for manufacturing activities. We separately include them as control variables in models (5) and (6), while we put them together in model (7). When considered separately, both variables turn out to be positive and statistically significant. However, this does not affect the sign and the significance of our core variables, i.e. $D$ and $D^{2}$. When included together, the two variables do not turn out to be significant instead, while the quadratic specification on $D$ keeps retaining its significance.

\section{INSERT TABLE 2 ABOUT HERE}

The results on Table 2 are obtained by running our regressions on an unbalanced panel of regions. In order to rule out the possibility that such are results are biased by the uneven distribution of observation across regions, we selected the regions showing observation over the whole time span, so as to get a balanced panel. The results of this 
further stream of regressions are reported in Table 3. One may note that our hypothesis turns out to be robust also to this check. Still, the specification of a quadratic relationship between $d A / A$ and $D$ holds significant. In particular, the signs of coefficients suggest that such relationship takes the shape of a quadratic curve with downward concavity. When the density of innovating increases, the rate at which productivity grows, keeps increasing at a decreasing rate up to a point beyond which it starts decreasing.

\section{INSERT TABLE 3 ABOUT HERE}

One more concern about the validity of our estimates may come from the pretty established evidence about the spatial correlation of productivity growth rates across neighbor regions. This means that cross-regional estimates of the determinants of productivity growth must control for spatial autocorrelation. The problem holds as well when dealing with a panel of $n$ regions observed over $T$ years. For this reason we also estimated equations (15) and (16), which specify the spatial autoregressive and the spatial error model respectively. Table 4 reports the results for the former estimation. Even in this case we provide a number of alternative models, so as to check for robustness.

\section{INSERT TABLE 4 ABOUT HERE}

In line with the existing literature, the coefficient on the spatially lagged dependent variable is positive and significant. This means that spatial autocorrelation is a relevant factor that needs to be controlled for. However, the signs and the significance for the density variables do not change as compared with the previous estimates, even in presence of control variables. Still, we observe a positive coefficient on $D$ and a negative coefficient on $D^{2}$. In table 5 we report the results we yielded by applying the spatial error model. 


\section{INSERT TABLE 5 ABOUT HERE}

Even in this case the coefficient for the spatial autocorrelation is positive and significant. Once more, the whole results are much in line with what described so far. The lagged levels of productivity retain the negative and significant coefficient. This captures possible mean reversion effects and signals that some (conditional) convergence dynamics might be at stake. The coefficients on $D$ and $D^{2}$ still show the expected signs. Productivity growth rates and the density of innovation activities are featured by a quadratic relationship characterized by a downward concavity. This results turned out to be robust to a pretty large of alternative specifications and robustness checks, and is quite consistent with the hypothesis according to which PKE are such that the net positive gains are likely to increase as the agglomeration of knowledge production processes increases, up to a critical point after which pecuniary losses start increasing at a more than proportionate rate with respect to pecuniary gains. As an effect net pecuniary gains turn out to decrease when the density levels go beyond the critical point, making the entry in markets for knowledge less and less attractive.

\section{Conclusions}

Building upon the notions of markets for knowledge and PKE, as distinct from technological externalities, we have been able to specify a quadratic relationship between the concentration of innovative activities at the regional level and their net positive effects. We were able to qualify the relationship between knowledge externalities and agglomeration as a quadratic function. Agglomeration yields positive net knowledge externalities only until a given threshold. Too much agglomeration and too dense knowledge transactions progressively dissipates the advantages in terms of 
knowledge externalities due to the emerging losses engendered by reduced appropriability.

The paper has provided a strong test for the hypotheses that a quadratic relationship takes place between technological concentration and total factor productivity growth for a large sample of European regions, in the time span ranging from 1995 to 2003.

The quadratic specification is a powerful result because it enables to identify the shifting relative advantage of regions in the location of knowledge intensive activities.

The identification of the notion of relative advantage in the location of knowledge intensive activities enables to identify the regions where it is not appropriate to invest in knowledge generating activities, the regions where it is 'more' convenient to invest in knowledge generating activities, and the regions where it would be better to reduce the levels of knowledge generating activities.

The strong econometric results enable to appreciate the implications of the quadratic specification in terms of output elasticity to additional knowledge intensive activities. It is clear in fact that by definition in a quadratic function the first derivative is stronger, the smaller the level of the concentration. Hence our findings confirm the hypothesis that the output elasticity of additional knowledge intensive activities is higher in peripheral rather than in core regions.

At a more practical level the quadratic specification and the results of the estimates according to which the maximum is well within the actual data, is a powerful and quite 
innovative tool to articulate the view that the dissemination of knowledge intensive activities may yield better results than their concentration. The implications for both innovation and regional policy in fact are relevant. First, it is not efficient to create excessive agglomeration of knowledge intensive activities: beyond a threshold, negative effects of agglomeration begin to take place. Second and most important, it is also clear that all investments in knowledge intensive activities are much more profitable, at the margin, in regions with lower level of agglomeration.

Innovation and regional policy interventions aimed to exploiting the positive effects of knowledge externalities stemming should design appropriate incentives to favor the dissemination of knowledge generating activities in regions with low levels of concentration in knowledge generating activities and prevent their excess concentration in a few spots.

At a more general level, the process of cluster formation and evolution should be viewed as a dynamic process driven by the interaction between centripetal and centrifugal forces, according to the mix of positive and negative effects of externalities. This allows us to revisit and re-appreciate the traditional Arrovian knowledge trade-off at a geographical level, with important policy implications. When centrifugal forces prevail, and firms valorize more the negative effect of spillovers in terms of nonappropriation of the returns to knowledge investments than their benefits, incentives to entering the cluster are not sufficient, the cluster can be undersized, interactions too weak and agglomeration economies cannot display their full positive effect. On the contrary, firms can agglomerate too much because of overcoming centripetal forces, with the effect that clusters are too big and the benefits of knowledge externalities are 
spoiled. The fine-tuning between centripetal and centrifugal forces drives the 'correct' evolution of the cluster, with a crucial role given to the intervention of the policy maker $^{16}$. Public intervention should not aim to favoring the generic agglomeration of knowledge intensive activities to reap the advantages of knowledge externalities but rather design selective incentives able to make, at the same time knowledge communication and dissemination more effective within local clusters and yet favor and help the appropriation of the returns to private investments in knowledge and innovation. The specific support to knowledge transactions and knowledge outsourcing between co-localized public research centers and private research and development activities within the frame of well designed intellectual property rights such as nonexclusive patents might at the same time favor the dissemination of knowledge and the process of knowledge sharing and yet implement the necessary conditions for knowledge appropriation and exploitation.

\footnotetext{
${ }^{16}$ This is not to put forward an argument for policy intervention against agglomeration and concentration, i.e. anti-urban regional policy. Instead, in the paper we wanted to draw attention on the possible negative consequences of excessive density of local innovation networks. These negative effects can harm the benefits stemming from agglomeration of knowledge-generating activities and should be taken into account by the policy maker when designing innovation policies and actions.
} 


\section{Appendix 1}

Table A - Correlation matrix, pooled sample

\begin{tabular}{|c|c|c|c|c|c|c|c|c|}
\hline 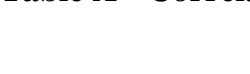 & $d \log A(t) / d t$ & $\ln A_{1}$ & $D_{t-1}$ & $D_{t-1}^{2}$ & SPZ & $D_{t-1} \cdot S P$ & $I Q_{1}$ & $A G_{1}$ \\
\hline$d \log A(t) / d t$ & 1 & & & & & & & \\
\hline $\ln A_{1}$ & 0.083 & 1 & & & & & & \\
\hline$D_{t-1}$ & 0.065 & 0.253 & 1 & & & & & \\
\hline$D_{t-1}^{2}$ & 0.040 & 0.067 & 0.886 & 1 & & & & \\
\hline$S P Z$ & -0.069 & -0.258 & -0.035 & 0.032 & 1 & & & \\
\hline$D_{t-1} \cdot S P$ & 0.065 & 0.188 & 0.978 & 0.925 & 0.027 & 1 & & \\
\hline$I Q_{1}$ & 0.002 & -0.147 & -0.169 & -0.079 & -0.171 & -0.161 & 1 & \\
\hline$A G_{1}$ & 0.103 & 0.305 & 0.212 & 0.066 & -0.260 & 0.161 & -0.251 & 1 \\
\hline
\end{tabular}




\section{References}

Abramovitz, M. 1956. Resource and output trends in the United States since 1870. American Economic Review 46: 5-23.

Acs, Z.J., Anselin, L. and Varga, A. 2002. Patents and innovation counts as measures of regional production of new knowledge. Research Policy 31: 1069-1085.

Agrawal, A., Cockburn, I and McHale, J. 2006. Gone but not forgotten: Knowledge flows, labor mobility, and enduring social relationships. Journal of Economic Geography 6: 571-591.

Aharonson, S. B., Baum, J. A. C. and Feldman, M. P. 2007. Desperately seeking spillovers? Increasing returns, social cohesion and the location of new entrants in geographic and technological space. Industrial and Corporate Change 16: 89-130.

Allen, R. C. 1983. Collective invention. Journal of Economic Behavior and Organization 4: 1-24.

Anselin, L. 1988. Spatial econometrics: Methods and models. Dordrecht: Kluwer.

Antonelli, C. 1999. The microdynamics of technological change. London: Routledge.

Antonelli, C. 2008a. Localized technological change: Towards the economics of complexity. London, Routledge.

Antonelli, C. 2008b. Pecuniary knowledge externalities: The convergence of directed technological change and the emergence of innovation systems. Industrial and Corporate Change 17: 1049-1070.

Arora, A., Fosfuri, A. and Gambardella, A. 2001. Markets for technology: The economics of innovation and corporate strategy. Cambridge, Mass: MIT Press.

Audretsch, D. B. and Feldman, M. 1996. Spillovers and the geography of innovation and production. American Economic Review 86: 630-640.

Beugelsdijk, S. 2007. The regional environment and a firm's innovative performance: A plea for a multilevel interactionist approach. Economic Geography 83:181-199.

Boschma, R. 2005. Proximity and innovation: A critical assessment. Regional Studies 39: 61-74.

Breschi, S. and Lissoni, F. 2001a. Localised knowledge spillovers vs. Innovative milieux: knowledge 'tacitness' reconsidered, Papers in Regional Science 80: 2001, 25573.

Breschi, S. and Lissoni, F. 2001b. Knowledge spillovers and local innovation systems: A critical survey, Industrial and Corporate Change 10, 975-1005. 
Cohen, W.M., Levinthal, D.A. 1989. Innovation and learning: The two faces of R\&D. Economic Journal 99: 569-596.

Cohen, W.M. and Levinthal, D.A. 1990. Absorptive capacity: A new perspective on learning and innovation. Administrative Science Quarterly 35: 128-152.

Crescenzi, R., Rodriguez-Pose, A. and Storper, M. 2007. The territorial dynamics of innovation: A Europe-United States comparative analysis. Journal of Economic Geography 7: 673-709.

Deckle, R. 2002. Industrial concentration and regional growth: Evidence from the prefectures. Review of Economics and Statistics 84: 310-315.

Dicken, P. and Malmberg, A. 2001. Firms in territories: A relational perspective. Economic Geography 77: 345-363.

Dumais, G., Ellison, G. and Glaeser, E. L. 2002. Geographic concentration as a dynamic process. Review of Economics and Statistics 84: 193-204.

Elhorst, P. J. 2003. Specification and estimation of spatial panel data models. International Regional Science Review 26: 244-268.

Feldman, M. A. 1999. The new economics of innovation, spillovers and agglomeration: A review of empirical studies. Economics of Innovation and New Technology 8: 5-25.

Feser, E. J. 2002. Tracing the sources of local external economies. Urban Studies 39: 2485-2506.

Foray, D. 2004. The economics of knowledge. Cambridge, Mass.: MIT Press.

Frenken, K., Van Oort, F. and Verburg, T. 2007. Related variety, unrelated variety and regional economic growth. Regional Studies 41: 685-697.

Giuliani, E. 2007. The selective nature of knowledge networks in clusters: Evidence from the wine industry. Journal of Economic Geography 7: 139-168.

Glaeser, E. L., Kallal, H., Scheinkman, J. and Shleifer, A. (1992), Growth in cities, Journal of Political Economy 100: 1126-1152.

Gossling, T. 2003. Proximity, trust and morality in networks. European Planning Studies 12: 675-689

Griliches, Z. 1979. Issues in assessing the contribution of research and development to productivity growth. Bell Journal of Economics 10: 92-116.

Griliches, Z. 1990. Patent statistics as economic indicators: A survey. Journal of Economic Literature 28: 1661-1707. 
Jaffe, A.B. 1986. Technological opportunity and spillover of R\&D: Evidence from firms' patents, profits and market value. American Economic Review 79: 985-1001.

Jaffe, A. B., Trajtenberg, M. and Henderson, R. 1993. Geographic localization of knowledge spillovers as evidenced by patent citations. Quarterly Journal of Economics 108: 577-598.

Jorgenson, D.W. 1995. Productivity volume 1: Post-war US economic growth. Cambridge, Mass: MIT Press.

Kremer, M. 1993. The O-Ring theory of economic development. Quarterly Journal of Economics 108: 551-575.

Herrigel, G. and Zeitlin, J. eds. 2004. Americanization and its limits: Reworking US technology and management in postwar Europe and Japan. Oxford: Oxford University Press.

Levin, R.C., Klevorich, A.K., Nelson, R.R. and Winter, S.G. 1987. Appropriating the returns from industrial research and development. Brooking Papers on Economic Activity 3: 783-831.

Le Sage, J.P. 1999. The theory and practice of spatial econometrics, Department of Economics, University of Toledo, available at www.spatial-econometrics.org.

Love, J. H. and Roper, S. 2009. Organizing the innovation process: complementarities in innovation networking. Industry and Innovation 16: 273-290.

Maddison, A. 1987. Growth and slowdown in advanced capitalist economies: Techniques of quantitative assessment. Journal of Economic Literature 25: 649-698.

Meade, J.E. 1952. External economies and diseconomies in a competitive situation, Economic Journal 62: 54-67.

Nakamura, K. and Odagiri, H. 2005. R\&D boundaries of the firm: An estimation of the double-hurdle model on commissioned $R \& D$, joint $R \& D$ and licensing in Japan. Economics of Innovation and New Technology 14: 583-615.

Nelson, R.R. 1982. The role of knowledge in R\&D efficiency. Quarterly Journal of Economics 97: 453-470.

Nicholas, T. 2009. Spatial diversity in invention: evidence from the early R\&D labs. Journal of Economic Geography 9: 1-31.

OECD. 2001. Measuring productivity. Measurement of aggregate and industry-level productivity growth. Paris: OECD Press.

Patrucco, P. P. 2005. The emergence of technology systems: Knowledge production and distribution in the case of the Emilian plastics districts. Cambridge Journal of Economics 29: 37-56. 
Patrucco, P. P. 2008. The economics of collective knowledge and technological communication. Journal of Technology Transfer 33: 579-599.

Patrucco, P. P. 2009. Collective knowledge production, costs and the dynamics of technological systems. Economics of Innovation and New Technology 18: 295-310.

Pavitt K. 1985. Patent statistics as indicators of innovative activities: Possibilities and problems. Scientometrics 7: 77-99.

Perroux F. 1955. Note sur la notion de 'pole de croissance', Èconomie Appliquèe, 7: 307-320.

Pisano, G. P. 1996. Learning before doing in the development of new process technology. Research Policy 25: 1097-1119.

Quatraro, F. 2009a. The diffusion of regional innovation capabilities: Evidence from Italian patent data, Regional Studies 43: 1333-1348.

Quatraro, F. 2009b. Innovation, structural change and productivity growth: Evidence from Italian regions, 1980-2003. Cambridge Journal of Economics 33: 1001-1022.

Roper, S., Du, J. and Love, J.H. 2008. Modelling the innovation value chain. Research Policy 37: 961-977.

Rosenthal, S. S. and Strange, W. C. 2003. Geography, industrial organization, and agglomeration. Review of Economics and Statistics 85: 377-393.

Scitovsky, T. 1954. Two concepts of external economies. Journal of Political Economy 62: 143-151.

Solow, R. 1957. Technical change and the aggregate production function. Review of Economics and Statistics 39: 312-320.

Stirling, A. 2007. A general framework for analyzing diversity in science, technology and society. Journal of the Royal Society Interface 15: 707-719.

Thompson, P. 2006. Patent citations and the geography of knowledge spillovers: evidence from inventor and examiner added citations. Review of Economics and Statistics. 82: 383-389.

Thompson, P. and Fox Kean, M. 2005. Patent citations and the geography of knowledge spillovers: A reassessment. American Economic Review 95 1: 450-460.

van den Berg, J.C.J.M. 2008. Optimal diversity: term Increasing returns versus recombinant innovation. Journal of Economic Behavior and Organization 68: 565-580.

Viner, J. 1931. Costs curves and supply curve. Zeitschrift für Nationalokonomie 3: 23 46. 
Von Hippel, E. 1988. The sources of innovation. Oxford: Oxford University Press.

Zahra, S. A. and George, G. 2002. Absorptive capacity: A review, re-conceptualization, and extension. Academy of Management Review 27: 185-203.

Zucker, L. G., Darby, M.R. and Armstrong. J.S. 1998. Geographically localized knowledge: Spillovers or markets? Economic Inquiry 36: 65-86.

Zucker, L. G., Darby, M.R. and Brewer, M. B. 1998. Intellectual human capital and the birth of U.S. biotechnology enterprises. American Economic Review 88: 290-306. 
Figure 1 - The costs and revenues from Knowledge Production as a function of $z$.

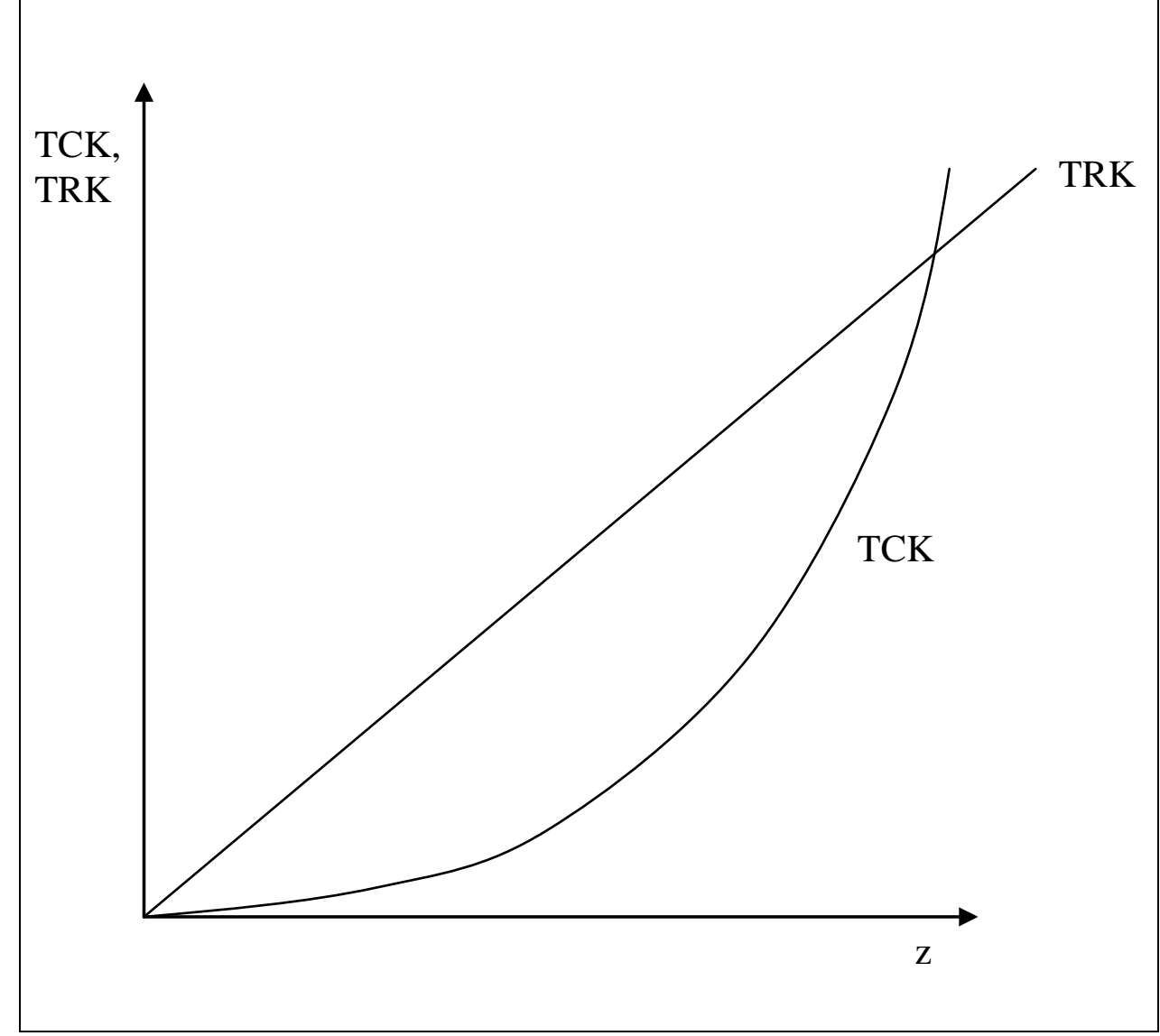


Figure 2 - The costs and revenues from Knowledge Production as a function of $D$.

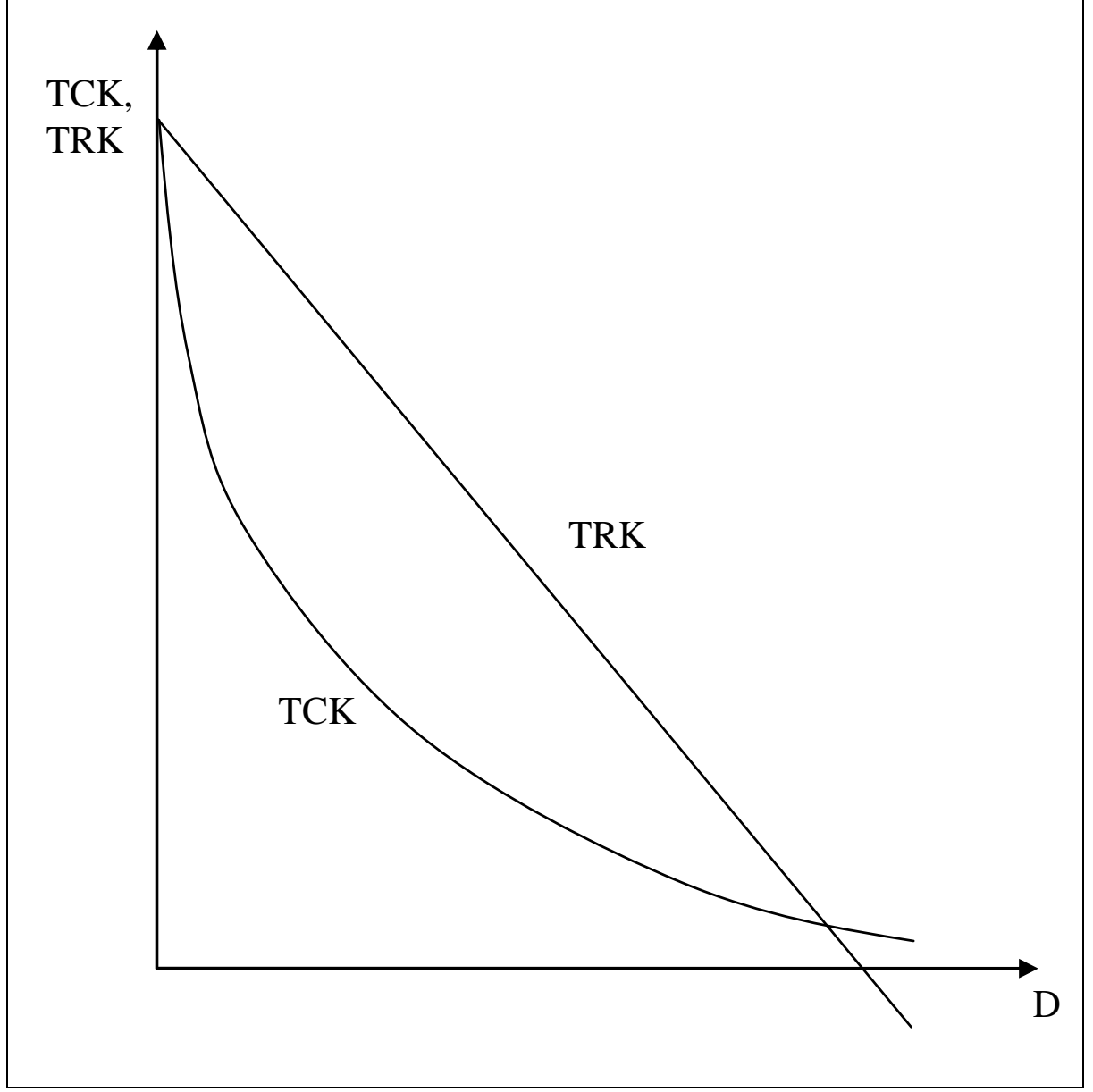


Figure 3

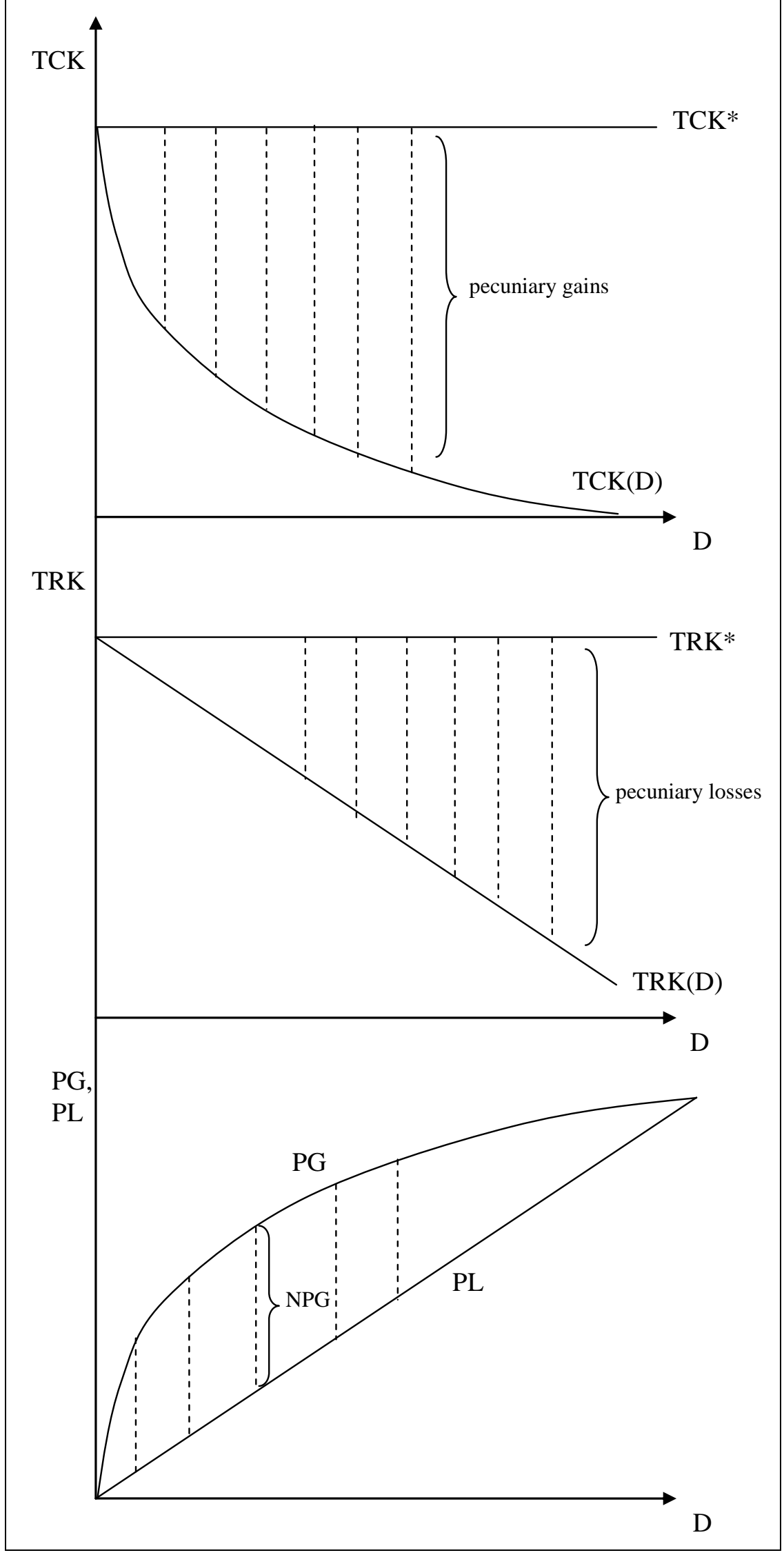


Figure 4

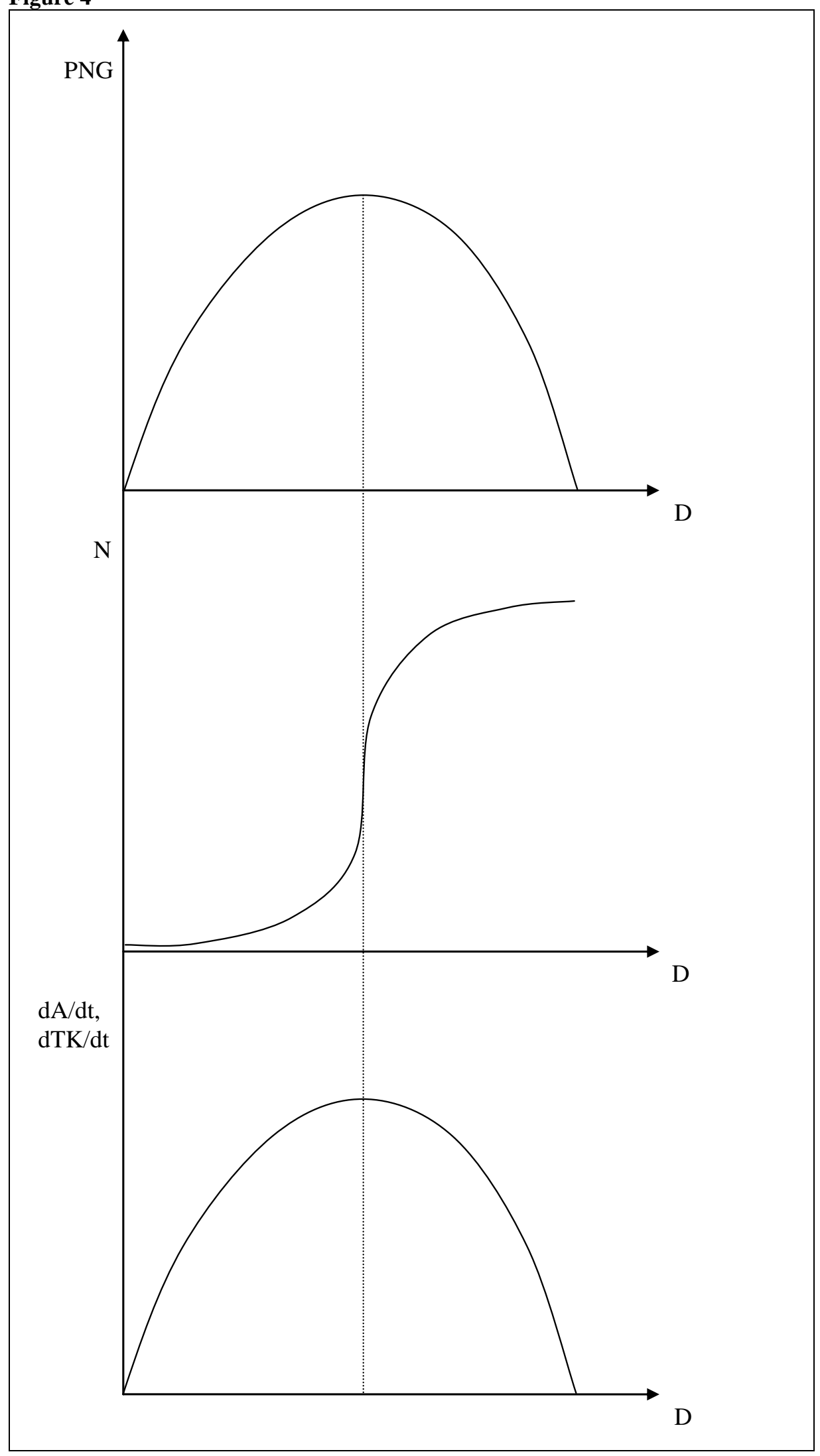

45 
Figure 5 - Regional Distribution of Patent Applications per 1000 Workers

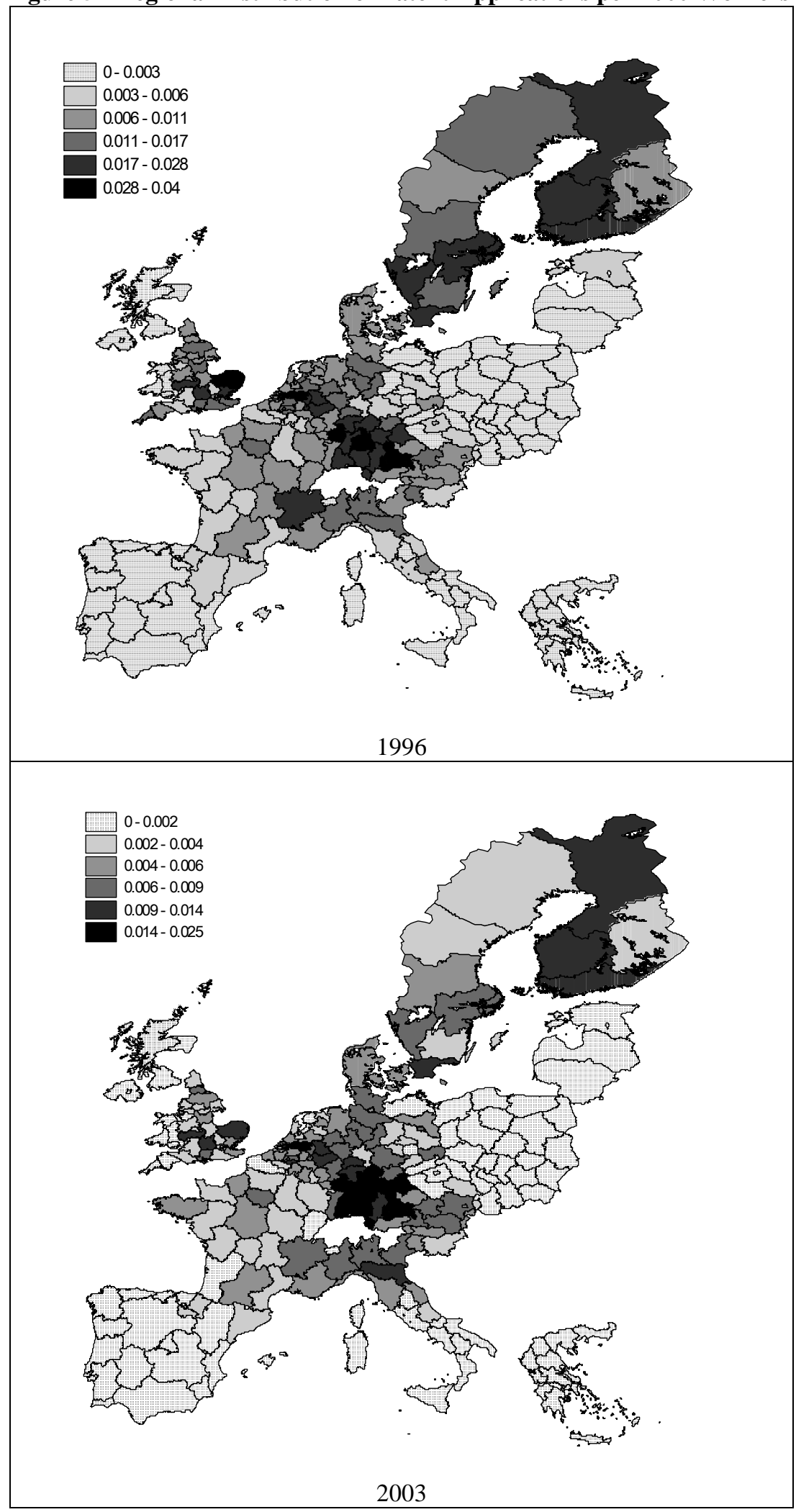


Table 1 - Descriptive Statistics for the Key Variables

\begin{tabular}{lccccc}
\hline \hline & Mean & \multicolumn{2}{c}{ St. Deviation } & Min & Max \\
\hline Growth rate of TFP & 0.012 & Within & Between & & 0.293 \\
\cline { 3 - 4 } & 0.029 & 0.043 & 0.036 & -0.136 & 0.515 \\
Growth rate of capital & 0.011 & 0.081 & 0.068 & -0.344 & 0.173 \\
Growth rate of labour & 11.0834 & 8.704 & 20.272 & 0.015 & 579.273 \\
$\begin{array}{l}\text { Patents per } \\
\text { Millions employees }\end{array}$ & & & & & \\
\hline \hline
\end{tabular}


Table 2 - Region TFP growth, panel data fixed effects estimates

\begin{tabular}{|c|c|c|c|c|c|c|c|}
\hline & 1 & 2 & 3 & 4 & 5 & 6 & 7 \\
\hline Constant & $\begin{array}{c}0.157^{* * *} \\
(0.065)\end{array}$ & $\begin{array}{c}0.178^{* * *} \\
(0.066)\end{array}$ & $\begin{array}{l}-0.039 \\
(0.061)\end{array}$ & $\begin{array}{l}-0.041 \\
(0.061)\end{array}$ & $\begin{array}{l}-2.14^{* * *} \\
(0.648)\end{array}$ & $\begin{array}{l}-0.011 \\
(0.061)\end{array}$ & $\begin{array}{l}-0.081 \\
(0.516)\end{array}$ \\
\hline $\ln _{t_{1}}$ & $\begin{array}{c}-0.051^{* *} \\
(0.024)\end{array}$ & $\begin{array}{c}-0.061^{* * *} \\
(0.024)\end{array}$ & $\begin{array}{c}0.017 \\
(0.022)\end{array}$ & $\begin{array}{c}0.017 \\
(0.023)\end{array}$ & $\begin{array}{c}0.032 \\
(0.024)\end{array}$ & $\begin{array}{c}0.002 \\
(0.022)\end{array}$ & $\begin{array}{c}0.034 \\
(0.025)\end{array}$ \\
\hline$D_{t-1}$ & $\begin{array}{l}0.181^{*} \\
(0.11)\end{array}$ & $\begin{array}{c}1.096^{* * *} \\
(0.405)\end{array}$ & $\begin{array}{c}1.484^{* * *} \\
(0.356)\end{array}$ & $\begin{array}{c}1.443^{* * *} \\
(0.459)\end{array}$ & $\begin{array}{c}1.348^{* * *} \\
(0.379)\end{array}$ & $\begin{array}{c}0.844^{* * *} \\
(0.277)\end{array}$ & $\begin{array}{l}0.717^{\text {*** }} \\
(0.287)\end{array}$ \\
\hline$D_{t-1}^{2}$ & & $\begin{array}{c}-2.441^{* * *} \\
(1.030)\end{array}$ & $\begin{array}{c}-3.52^{* * *} \\
(0.903)\end{array}$ & $\begin{array}{c}-3.509 * * * \\
(0.907)\end{array}$ & $\begin{array}{c}-3.294^{* * *} \\
(0.961)\end{array}$ & $\begin{array}{c}-2.051^{* * *} \\
(0.707)\end{array}$ & $\begin{array}{c}-1.707^{* *} \\
(0.707)\end{array}$ \\
\hline SPA & & & $\begin{array}{c}0.015 \\
(0.012)\end{array}$ & $\begin{array}{c}0.015 \\
(0.012)\end{array}$ & $\begin{array}{c}0.009 \\
(0.013)\end{array}$ & $\begin{array}{l}-0.013 \\
(0.012)\end{array}$ & \\
\hline$D_{t-1} \cdot S P Z$ & & & & $\begin{array}{c}0.012 \\
(0.841)\end{array}$ & & & \\
\hline$A F_{1}$ & & & & & $\begin{array}{c}0.399^{* * *} \\
(0.127)\end{array}$ & & $\begin{array}{l}-0.081 \\
(0.101)\end{array}$ \\
\hline$I Q_{1}$ & & & & & & $\begin{array}{c}0.054^{* *} \\
(0.0273)\end{array}$ & $\begin{array}{c}0.029 \\
(0.038)\end{array}$ \\
\hline Obs. & 827 & 827 & 701 & 701 & 633 & 514 & 457 \\
\hline$R^{2}$ & 0.21 & 0.22 & 0.27 & 0.27 & 0.30 & 0.40 & 0.43 \\
\hline
\end{tabular}


Table 3 - Region TFP growth, panel data fixed effects estimates

\begin{tabular}{|c|c|c|c|c|c|c|c|}
\hline & 1 & 2 & 3 & 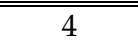 & $\overline{5}$ & $\bar{~} 6$ & $\overline{77}$ \\
\hline Constant & $\begin{array}{c}0.153^{* *} \\
(0.69)\end{array}$ & $\begin{array}{c}0.176^{* * *} \\
(0.070)\end{array}$ & $\begin{array}{c}0.005 \\
(0.063)\end{array}$ & $\begin{array}{c}-0.001 \\
(0.0645)\end{array}$ & $\begin{array}{c}-1.763^{* * *} \\
(0.595)\end{array}$ & $\begin{array}{c}0.020 \\
(0.061)\end{array}$ & $\begin{array}{c}0.515 \\
(0.478)\end{array}$ \\
\hline $\ln A_{1}$ & $\begin{array}{c}-0.052^{* *} \\
(0.025)\end{array}$ & $\begin{array}{c}-0.064^{* * *} \\
(0.026)\end{array}$ & $\begin{array}{c}0.006 \\
(0.024)\end{array}$ & $\begin{array}{l}0.008 \\
(0.024)\end{array}$ & $\begin{array}{c}0.028 \\
(0.025)\end{array}$ & $\begin{array}{l}-0.006 \\
(0.021)\end{array}$ & $\begin{array}{c}0.014 \\
(0.026)\end{array}$ \\
\hline$D_{t-1}$ & $\begin{array}{l}0.178^{*} \\
(0.103)\end{array}$ & $\begin{array}{c}1.026^{* * *} \\
(0.384)\end{array}$ & $\begin{array}{c}1.502^{* * *} \\
(0.342)\end{array}$ & $\begin{array}{c}1.360^{* * *} \\
(0.442)\end{array}$ & $\begin{array}{c}1.365^{\star * *} \\
(0.359)\end{array}$ & $\begin{array}{c}0.742^{* * *} \\
(0.270)\end{array}$ & $\begin{array}{l}0.604^{* *} \\
(0.275)\end{array}$ \\
\hline$D_{t-1}^{2}$ & & $\begin{array}{c}-2.239^{* *} \\
(0979)\end{array}$ & $\begin{array}{c}-3.522^{* * *} \\
(0.864)\end{array}$ & $\begin{array}{c}-3.479 * * * \\
(0.869)\end{array}$ & $\begin{array}{c}-3.281^{* * *} \\
(0.904)\end{array}$ & $\begin{array}{c}-1.774^{* * *} \\
(0.688)\end{array}$ & $\begin{array}{r}-1.402^{* *} \\
(0.707)\end{array}$ \\
\hline SPA & & & $\begin{array}{c}0.010 \\
(0.013)\end{array}$ & $\begin{array}{c}0.009 \\
(0.013)\end{array}$ & & $\begin{array}{l}-0.016 \\
(0.013)\end{array}$ & \\
\hline$D_{t-1} . S P A$ & & & & $\begin{array}{l}0.406 \\
(0.797)\end{array}$ & & & \\
\hline$\Delta \sigma_{1}$ & & & & & $\begin{array}{c}0.331^{* * *} \\
(0.118)\end{array}$ & & $\begin{array}{c}0.014 \\
(0.038)\end{array}$ \\
\hline$I O_{1}$ & & & & & & $\begin{array}{c}0.029 \\
(0.030)\end{array}$ & $\begin{array}{l}-0.109 \\
(0.093)\end{array}$ \\
\hline Obs. & 560 & 560 & 472 & 472 & 424 & 424 & 424 \\
\hline$R^{2}$ & 0.21 & 0.22 & 0.26 & 0.26 & 0.29 & 0.46 & 0.47 \\
\hline
\end{tabular}


Table 4 - Regional TFP Growth, Spatial Autoregressive Model for panel data

\begin{tabular}{|c|c|c|c|c|c|c|}
\hline & 1 & 2 & 3 & 4 & 5 & 6 \\
\hline 7 & $\begin{array}{l}0.256^{\star *} \\
(2.054)\end{array}$ & $\begin{array}{c}0.403^{* * *} \\
(3.822)\end{array}$ & $\begin{array}{l}0.257^{* *} \\
(2.049)\end{array}$ & $\begin{array}{c}0.399^{* * *} \\
(3.757)\end{array}$ & $\begin{array}{l}0.243^{* *} \\
(1.941)\end{array}$ & $\begin{array}{c}0.380^{* * *} \\
(3.53)\end{array}$ \\
\hline $\ln 4_{1}$ & $\begin{array}{c}-0.315^{* * *} \\
(-7.77)\end{array}$ & $\begin{array}{c}-0.288^{* * *} \\
(-7.551)\end{array}$ & $\begin{array}{c}-0.316^{* * *} \\
(.7 .794)\end{array}$ & $\begin{array}{c}-0.289 * * * \\
(-7.57)\end{array}$ & $\begin{array}{c}-0.327^{* * *} \\
(-7.955)\end{array}$ & $\begin{array}{c}-0.301^{* * *} \\
(-7.824)\end{array}$ \\
\hline$D_{t-1}$ & $\begin{array}{l}2.48^{* * *} \\
(4.105)\end{array}$ & $\begin{array}{c}2.079^{* * *} \\
(3.899)\end{array}$ & $\begin{array}{c}2.491^{* * *} \\
(4.117)\end{array}$ & $\begin{array}{c}2.103^{* * *} \\
(3.939)\end{array}$ & $\begin{array}{c}3.345^{* * *} \\
(4.176)\end{array}$ & $\begin{array}{c}3.070^{* * *} \\
(4.422)\end{array}$ \\
\hline$D_{t-1}^{2}$ & $\begin{array}{c}-5.313^{* * *} \\
(-3.435)\end{array}$ & $\begin{array}{c}-4.389^{* * *} \\
(-3.123)\end{array}$ & $\begin{array}{c}-5.323^{* * *} \\
(-3.447)\end{array}$ & $\begin{array}{c}-4.447^{* * *} \\
(-3.161)\end{array}$ & $\begin{array}{c}-5.608^{* * *} \\
(-3.587)\end{array}$ & $\begin{array}{c}-4.594^{* * *} \\
(-3.265)\end{array}$ \\
\hline SPA & & & $\begin{array}{c}0.010 \\
(0.436)\end{array}$ & $\begin{array}{c}0.011 \\
(0.483)\end{array}$ & $\begin{array}{c}0.018 \\
(0.782)\end{array}$ & $\begin{array}{c}0.022 \\
(0.942)\end{array}$ \\
\hline$D_{t-1} \cdot S P Z$ & & & & & $\begin{array}{c}-2.417^{* *} \\
(-1.72)\end{array}$ & $\begin{array}{c}-2.990^{* * *} \\
(-2.176)\end{array}$ \\
\hline Regional dummies & Yes & Yes & Yes & Yes & Yes & Yes \\
\hline Time dummies & No & Yes & No & Yes & No & Yes \\
\hline Obs. & 424 & 424 & 424 & 424 & 424 & 424 \\
\hline Log-likelihood & 792.083 & 757.624 & 792.201 & 757.583 & 793.397 & 761.846 \\
\hline$R^{2}$ & 0.27 & 0.24 & 0.27 & 0.24 & 0.28 & 0.24 \\
\hline
\end{tabular}


Table 5 - Regional TFP Growth, Spatial Error Model for panel data

\begin{tabular}{|c|c|c|c|c|c|c|}
\hline & 1 & 2 & 3 & $\overline{44}$ & $\overline{5}$ & $\overline{6}$ \\
\hline $\ln A_{1}$ & $\begin{array}{c}-0.316^{* * *} \\
(-7.904)\end{array}$ & $\begin{array}{l}-0.312^{* * *} \\
(-7.860)\end{array}$ & $\begin{array}{c}-0.316^{* * *} \\
(-7.922)\end{array}$ & $\begin{array}{c}-0.313^{* * *} \\
(-7.856)\end{array}$ & $\begin{array}{c}-0.328^{* * *} \\
(-8.095)\end{array}$ & $\begin{array}{c}-0.329^{* * *} \\
(-8.271)\end{array}$ \\
\hline$D_{t-1}$ & $\begin{array}{c}3.105^{* * *} \\
(4.966)\end{array}$ & $\begin{array}{c}2.906^{* * *} \\
(5.046)\end{array}$ & $\begin{array}{c}3.084^{* * *} \\
(4.925)\end{array}$ & $\begin{array}{c}2.913^{* * *} \\
(5.051)\end{array}$ & $\begin{array}{c}3.889^{* * *} \\
(4.734)\end{array}$ & $\begin{array}{c}4.288^{* * *} \\
(5.810)\end{array}$ \\
\hline$D_{t-1}^{2}$ & $\begin{array}{c}-6.715^{* * *} \\
(-4.233)\end{array}$ & $\begin{array}{c}-6.327^{* * *} \\
(-4.186)\end{array}$ & $\begin{array}{c}-6.669^{* * *} \\
(-4.199)\end{array}$ & $\begin{array}{c}-6.344^{* * *} \\
(-4.194)\end{array}$ & $\begin{array}{c}-7.044^{* * *} \\
(-4.396)\end{array}$ & $\begin{array}{c}-6.547^{* * *} \\
(-4.377)\end{array}$ \\
\hline$M I_{1}$ & & & $\begin{array}{c}0.015 \\
(0.663)\end{array}$ & $\begin{array}{c}0.006 \\
(0.256)\end{array}$ & $\begin{array}{c}0.022 \\
(0.937)\end{array}$ & $\begin{array}{c}0.022 \\
(0.895)\end{array}$ \\
\hline$D_{t-1} \cdot M I_{t}$ & & & & & $\begin{array}{c}-2.132 \\
(-1.523)\end{array}$ & $\begin{array}{c}-4.256^{* * *} \\
(-2.961)\end{array}$ \\
\hline $\begin{array}{l}\text { Spatial } \\
\text { Autocorrelation }\end{array}$ & $\begin{array}{c}0.503^{* * *} \\
(4.341)\end{array}$ & $\begin{array}{c}0.469^{* * *} \\
(3.801)\end{array}$ & $\begin{array}{c}0.507^{* * *} \\
(4.409)\end{array}$ & $\begin{array}{c}0.475^{\star * *} \\
(3.891)\end{array}$ & $\begin{array}{c}0.491^{* * *} \\
(4.143)\end{array}$ & $\begin{array}{c}0.439^{* * *} \\
(3.379)\end{array}$ \\
\hline Regional dummies & Yes & Yes & Yes & Yes & Yes & Yes \\
\hline Time dummies & No & Yes & No & Yes & No & Yes \\
\hline Obs. & 424 & 424 & 424 & 424 & 424 & 424 \\
\hline Log-likelihood & 795.629 & 759.848 & 795.847 & 759.879 & 796.993 & 764.164 \\
\hline$R^{2}$ & 0.29 & 0.16 & 0.29 & 0.16 & 0.30 & 0.19 \\
\hline
\end{tabular}

